\title{
Development and Optimization of a Germination Assay and Long-Term Storage for Cannabis sativa Pollen
}

\author{
Daniel Gaudet, Narendra Singh Yadav ${ }^{\mathbb{D}}$, Aleksei Sorokin, Andriy Bilichak ${ }^{\dagger}$ and \\ Igor Kovalchuk * \\ Department of Biological Sciences, University of Lethbridge, Lethbridge, AB T1K 3M4, Canada; \\ daniel.gaudet@uleth.ca (D.G.); narendra.yadav@uleth.ca (N.S.Y.); aleksei.sorokin@uleth.ca (A.S.); \\ a.bilichak@gmail.com (A.B.) \\ * Correspondence: igor.kovalchuk@uleth.ca \\ + Current address: Morden Research and Development Center, Agriculture and Agri-Food Canada, \\ Morden, MB R6M 1Y5, Canada.
}

Received: 21 April 2020; Accepted: 20 May 2020; Published: 23 May 2020

\begin{abstract}
Pollen viability and storage is of great interest to cannabis breeders and researchers to maintain desirable germplasm for future use in breeding or for biotechnological and gene editing applications. Here, we report a simple and efficient cryopreservation method for long-term storage of Cannabis sativa pollen. Additionally, the bicellular nature of cannabis pollen was identified using DAPI (4',6-diamidino-2-phenylindole) staining. A pollen germination assay was developed to assess cannabis pollen viability and used to demonstrate that pollen collected from different principal growth stages exhibited differential longevity. Finally, a simple and efficient method that employs pollen combined with baked whole wheat flour and subsequent desiccation under vacuum was developed for the long-term cryopreservation of $C$. sativa pollen. Using this method, pollen viability was maintained in liquid nitrogen after four months, suggesting long-term preservation of cannabis pollen.
\end{abstract}

Keywords: Cannabis sativa; pollen germination assay; cryopreservation; long-term storage; DAPI staining of germinated pollen; vegetative nuclei; sperm nuclei

\section{Introduction}

Cannabis or hemp (Cannabis sativa L.) is an annual, primarily dioecious flowering plant. The center of origin is in Central Asia, and it has been bred for thousands of years for a variety of traits, including fiber, oil, seed and drug use [1]. Cannabis is a diploid plant $(2 n=20)$ and males are characterized by heterogametic chromosomes $(X Y)$ with homogametic chromosomes $(X X)$ conferring the female phenotype. Male plants produce flowers containing stamens producing pollen whereas female plants develop ovaries that produce seed following pollination. Female inflorescences are characterized by secretory hairs known as glandular trichomes, which produce a resinous mix of cannabinoids and aromatic compounds that are valued for both medical therapeutics and recreational effects [2].

Pollen viability is of great interest to breeders and researchers alike. Breeding projects may wish to store pollen for extended periods of time, where high value genetic material may be stored for future use or for biotechnological and gene editing applications that requires a quick and effective method for determining pollen viability [3-5]. Fluorescent stains such as fluorescein diacetate (FDA) or fluorochromatic reaction test (FCR) have been previously reported for assessing pollen viability in cannabis $[3,4]$. Viability is not always correlated with germination, as pollen may retain the ability to metabolize while losing its ability to germinate [5]. To better assess germination, we established a pollen germination assay (PGA) to estimate germination rates. We also adapted a DAPI 
(4',6-diamidino-2-phenylindole) stain to visualize pollen pre- and post-germination, and to establish whether Cannabis sativa pollen was a bicellular or tricellular, which to our knowledge has not been reported in the literature. In approximately 30\% of angiosperms, pollen is tricellular, with the male gametophyte sexually mature at the time of anthesis [6]. We also used the PGA to test how storage and timing of pollen collection influences germination rates. Pollen germination rates were assessed over a period when stored at $4{ }^{\circ} \mathrm{C}$ from males at different stages of floral development. Finally, we developed a simple procedure for the long-term storage of cannabis pollen using desiccation with baked whole wheat flower followed by cryopreservation, which potentially maintains long-term viability of pollen for future use.

\section{Results and Discussion}

\subsection{Optimization of Pollen Germination for PGA}

To obtain a representation of the germination profile, a time-lapse of a pollen germination assay (PGA) was evaluated using microscopy. We observed the germination profile for $6 \mathrm{~h}$ with $30 \mathrm{~min}$ interval. The final germination was calculated after $16 \mathrm{~h}$ incubation. Germination started within $30 \mathrm{~min}$ with extending pollen tubes clearly visible (Figure 1 and Video S1).

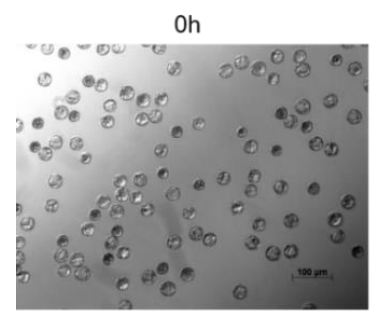

3h

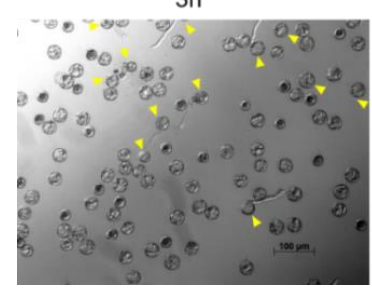

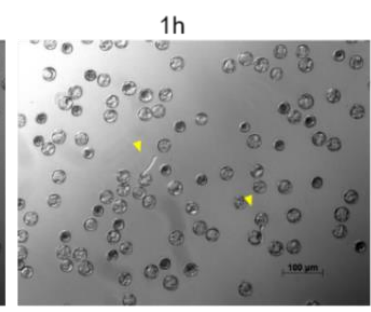

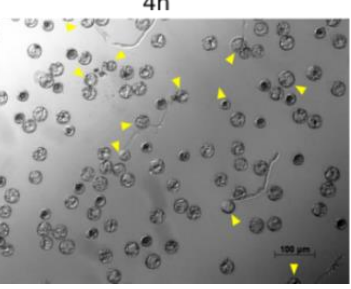

$5 \mathrm{~h}$

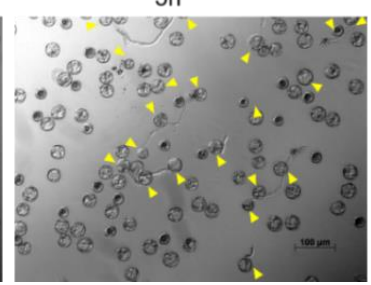

$2 \mathrm{~h}$

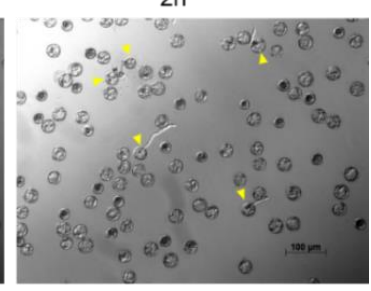

$6 \mathrm{~h}$

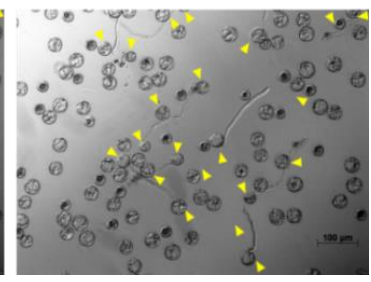

Figure 1. Representative photographs of cannabis pollen germination profile. Images were taken at 30 -min intervals for $6 \mathrm{~h}$ with germinating pollen grains indicated by the yellow arrows. Germination started within $30 \mathrm{~min}$ with extending pollen tubes clearly visible. Images were acquired using an inverted fluorescent microscope (Zeiss Axio Observer Z1, Germany).

Cannabis pollen readily germinated in the Pollen Germination Media (PGM). PGM was evaluated both as a liquid and a solid media (1\% agar). Germination rates were comparable in both media; however, pollen tubes were not as easily imaged under the microscope when germinated on solid agar medium (data not shown). For this reason, we opted for performing the PGA using liquid media. Of the different concentrations of pollen tested, $0.1 \mathrm{mg} / \mathrm{mL}$ provided the clearest imaging of germination, as higher concentrations resulted in crowding in the test well that reduced visibility (Figure 2). Additionally, in the highest density treatment, germination was adversely affected and made it difficult to accurately quantify germination percentage (Figure 2). 


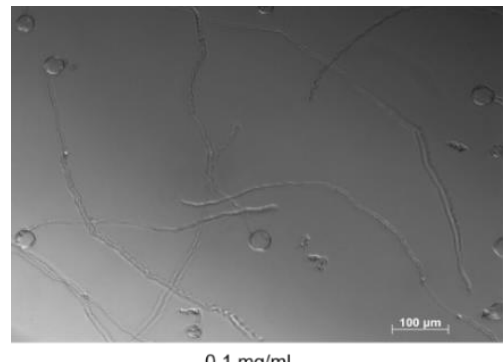

$0.1 \mathrm{mg} / \mathrm{mL}$

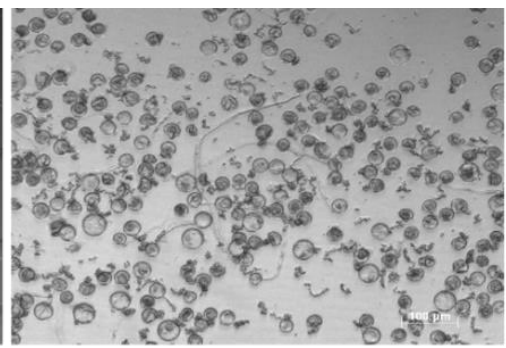

$1 \mathrm{mg} / \mathrm{mL}$

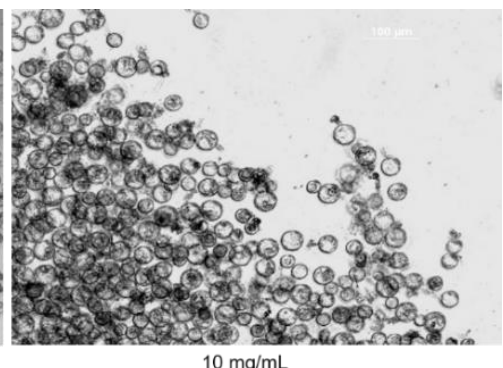

$10 \mathrm{mg} / \mathrm{mL}$

Figure 2. Optimization of the Pollen Germination Assay. Cannabis pollen germination in PGM at concentrations of $0.1,1$ and $10 \mathrm{mg} / \mathrm{mL}$. Images were acquired after $16 \mathrm{~h}$ using an inverted fluorescent microscope (Zeiss Axio Observer Z1, Germany).

\subsection{Pollen Collected at Different Principal Growth Stages Exhibits Different Longevity}

To establish how cannabis pollen germination rates change over time, we tested the pollen in a pollen germination assay after storage at $4{ }^{\circ} \mathrm{C}$. Because pollen collected from different principal growth stages may affect germination rates, we collected pollen from male flowers at four different points during floral development to cover the entirety of anthesis (Figure S1).

We compared the loss of viability of cannabis pollen collected from the four different points during flower development over the course of 21 days. The rate of germination at $\mathrm{T} 0$ was $33 \%$ for Early (62), $46 \%$ for Mid (64), 50\% for Mid-Late (65) and 41\% for Late (64) stage (Figure 3). All stages lost viability after only one week at $4{ }^{\circ} \mathrm{C}$ storage, except Mid (64) (Figure 3). After 21 days storage at $4{ }^{\circ} \mathrm{C}$, pollen collected from Early (62), Mid-Late (65) and Late (67) stages, lost their viability (approached $0 \%$ germination). However, pollen collected from the Mid flowering stage (64) retained viability the longest with $22 \%$ of pollen grains successfully germinated after 21 days storage at $4{ }^{\circ} \mathrm{C}$ (Figure 3 ). This suggested that an optimal growth stage for pollen collection is around the developmental stage (64), whereas the loss of pollen viability may begin while the pollen is still present in the anthers. Pollen collected earlier, at developmental stage 62 may not have fully matured, resulting in a lower germination percentage (Figure 3).

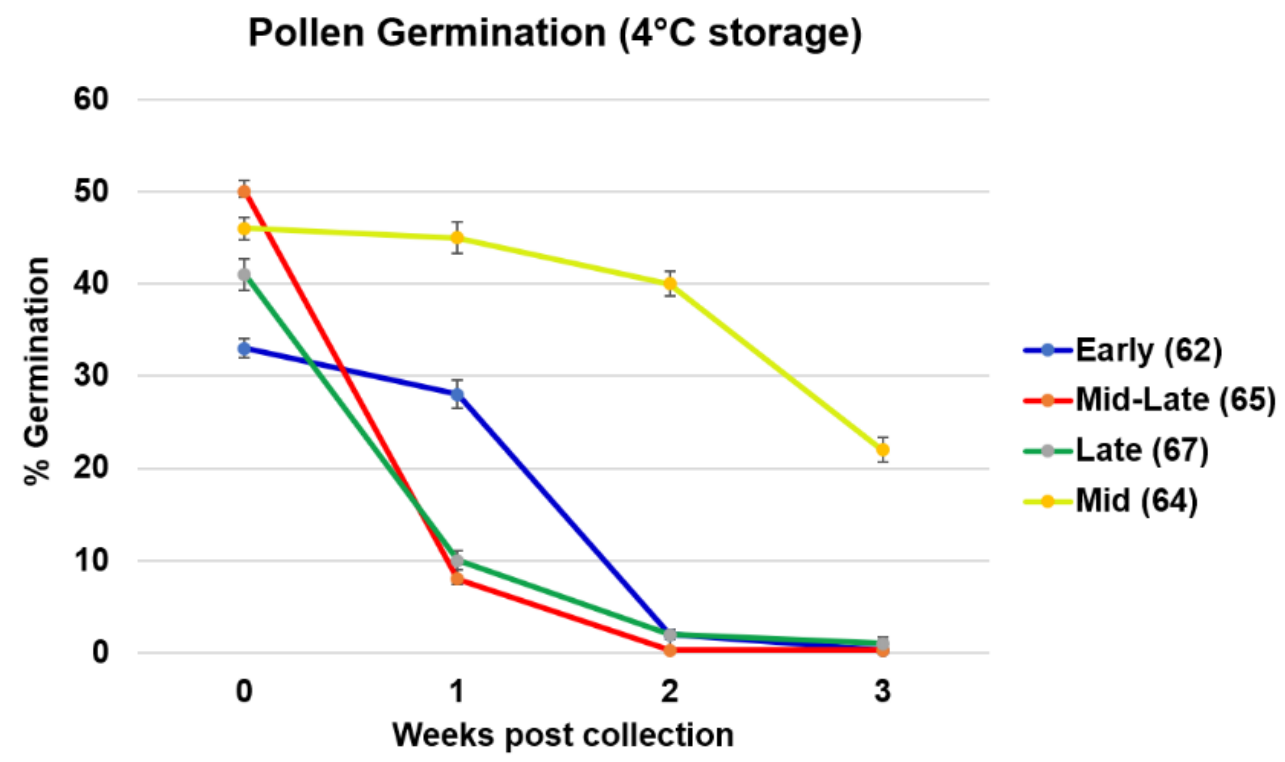

Figure 3. Loss of pollen viability over time. Pollen was harvested from plants at four different developmental stages then stored at $4{ }^{\circ} \mathrm{C}$ for one to three weeks. Viability was determined via pollen germination assay. Data were shown as mean $\pm \mathrm{SE}(n=9)$. 


\subsection{DAPI Staining Revealed Bicellular Nature of Cannabis Pollen}

While the fluorescein diacetate (FDA) stain is routinely used for viability tests, it is not ideal for visualizing the nuclei in pollen cells. In order to establish whether cannabis pollen was bicellular or tricellular, we performed a DAPI stain on germinating cannabis pollen. Prior to pollen tube germination, the brighter, more compact sperm nucleus and the diffuse vegetative nucleus were visible (Figure $4 \mathrm{~A}, \mathrm{~B}$ ). The brighter staining in the sperm nucleus represents the more condensed state of chromatin compared to the more transcriptionally active vegetative nucleus. Following pollen tube germination, both sperm nuclei are clearly visible as they descend the pollen tube (Figure 4C). This suggests that cannabis releases sexually immature pollen grains, with the second mitosis event occurring after pollen tube germination.
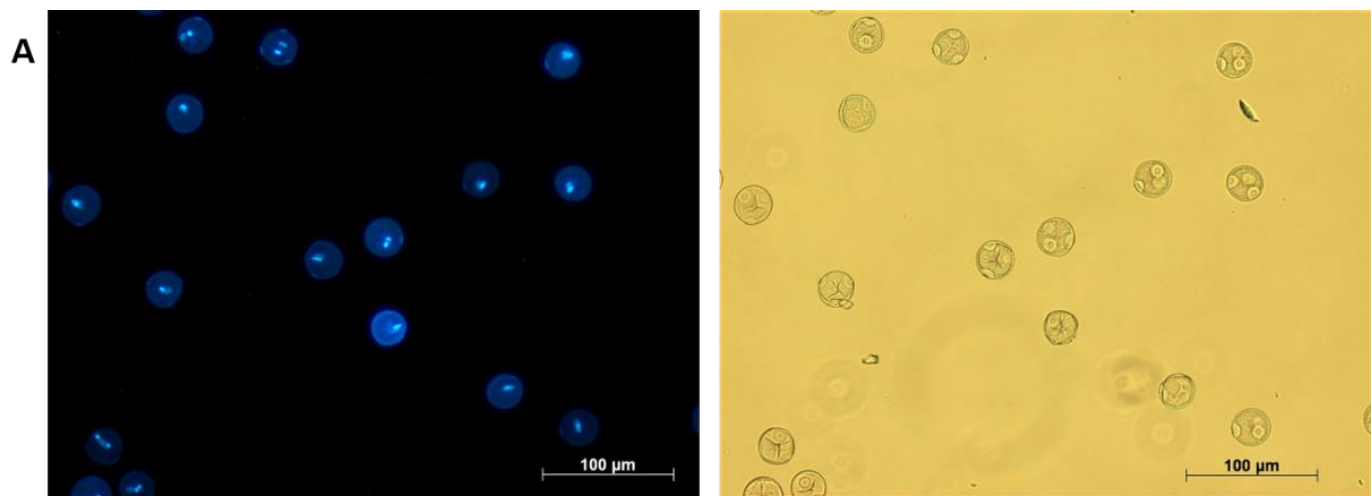

B
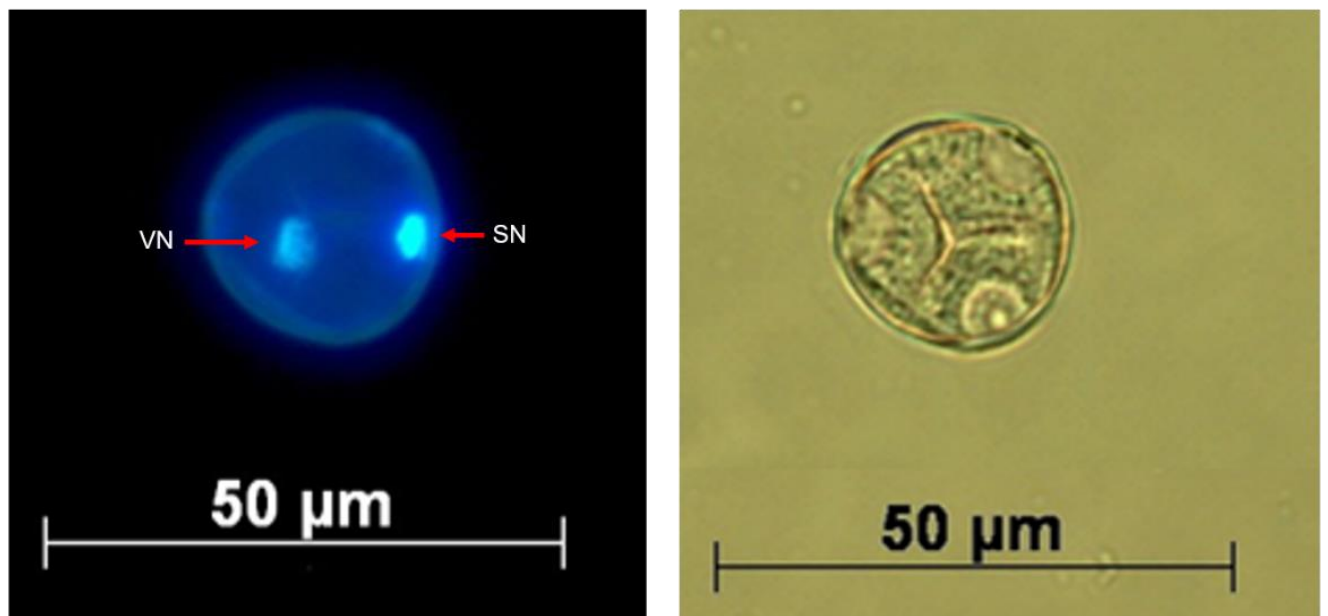

C
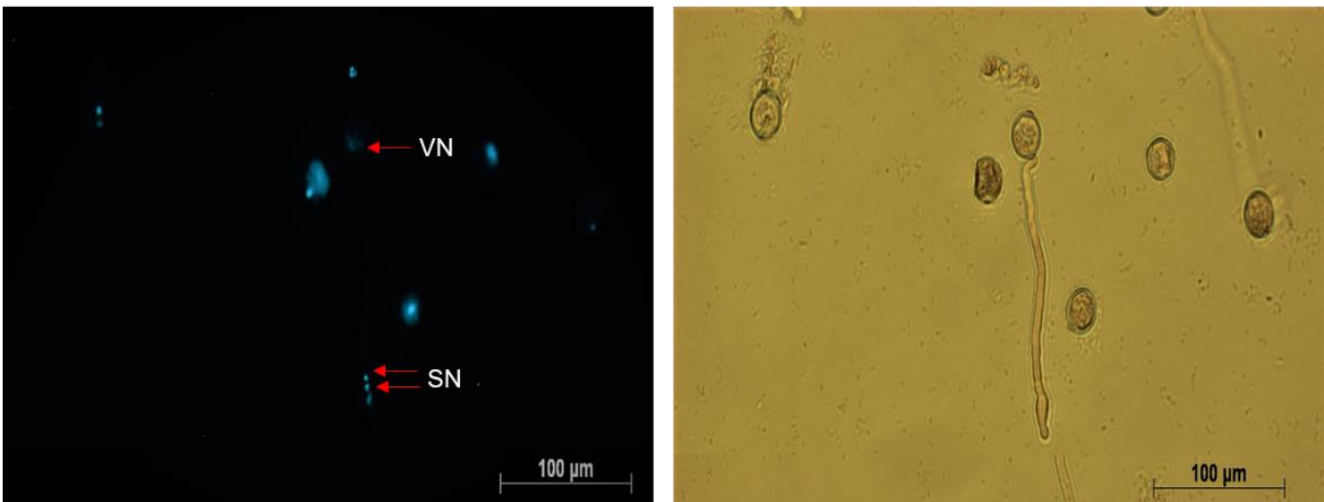

Figure 4. Visualization of cannabis pollen at different stages of germination using DAPI staining. Both the sperm (SN) and the vegetative nuclei (VN) are visible at the bicellular stage prior to pollen tube germination (A, B). Image $(\mathbf{C})$ represents a germinated cannabis pollen cell. 


\subsection{Development of a Cryopreservation Method for Cannabis Pollen}

Pollen cryopreservation has been employed in a variety of agriculturally and medicinally important plant species for the preservation of elite germplasm. Numerous studies have reported the data on pollen viability under various storage conditions [5,7]. While the interaction between pollen water content and viability is complex, it is understood that optimum water content is necessary for longevity [5]. Generally, longevity is increased by lowering the temperature and moisture content. Some reports indicate a moisture optima of $15 \%$, while higher water concentrations (above 30\%) may result in rapid deterioration during cryopreservation [8]. Liquid Nitrogen $\left(\mathrm{LN} ;-196{ }^{\circ} \mathrm{C}\right)$ is routinely used for cryogenic storage, as it is relatively cheap, safe and maintains a temperature where enzymatic and chemical reactions do not cause biological deterioration [9]. Cannabis pollen stored in LN without prior desiccation failed to germinate (Figure S2). Pollen cells with high moisture levels do not survive cryogenic storage, presumably due to intracellular ice formation [5]. Therefore, pollen cells need to be dried within a range where no freezable water exists without succumbing to desiccation injury. For pollen desiccation, we tested a vacuum desiccation at pressures of 5,15 or $25 \mathrm{kPa}$ for either 20 or $40 \mathrm{~min}$. When pollen was desiccated prior to storage in LN, it failed to germinate (Figure S2), suggesting that desiccation alone may not be sufficient for pollen viability during cryopreservation. Therefore, in addition to desiccation, we also tested cellular cryoprotectants, such as DMSO and glycerol that have been reported to improve cell survival after cryogenic storage [10]. Desiccated cannabis pollen combined with a $10 \%, 20 \%, 30 \%$ or $60 \%$ DMSO or glycerol solution prior to being stored in LN for $24 \mathrm{~h}$ exhibited $0 \%$ germination (Figure S2).

Baked wheat flour has been previously suggested as a possible cryoprotectant for long term pollen storage [11]. To test whether baked wheat flour can be used as a cryoprotectant for cannabis pollen, cannabis pollen was desiccated and combined with baked wheat flour. Vacuum desiccation at a lower pressure of $5 \mathrm{kPa}$ for the longest interval for $40 \mathrm{~min}$, resulted in the highest germination rate after storage in LN after $24 \mathrm{~h}$ (Figure 5). Pollen germination did not occur at higher pressures, as the cells may have been compromised during the drying process. This treatment was used for subsequent preservation experiments where the GLM test results indicated no significant differences in germination rate between $24 \mathrm{~h} \mathrm{LN}$ stored pollen and the non-LN control pollen $(p>0.05)$ that was subjected to the same desiccation protocol and combined with whole wheat flour (Figure 6). Desiccation itself caused approximately 50\% reduction in germination as compared to untreated freshly harvested pollen (Figures 3 and 6). Desiccated cannabis pollen combined with baked wheat flour was kept in LN for four months to test long term storage. The GLM test results indicated that there was no significant difference observed as compared to non-LN control and $24 \mathrm{~h}$ LN stored pollen $(p>0.05)$ (Figure 6), suggesting long term storage is a possibility under appropriate conditions. To confirm in planta viability of the treated cannabis pollen, the pollen/wheat flour mix was removed from LN and applied to flowering female cannabis plants. The pollination resulted in successful seed formation in all the flowers receiving treated pollen. Once the female had finished flowering, the flower material was collected and processed for seeds. Seed number, size and morphology from the cryopreserved pollen were similar to those obtained using untreated fresh pollen (Figure S3). Collected seeds were germinated to ensure viability, with no abnormalities noted. 

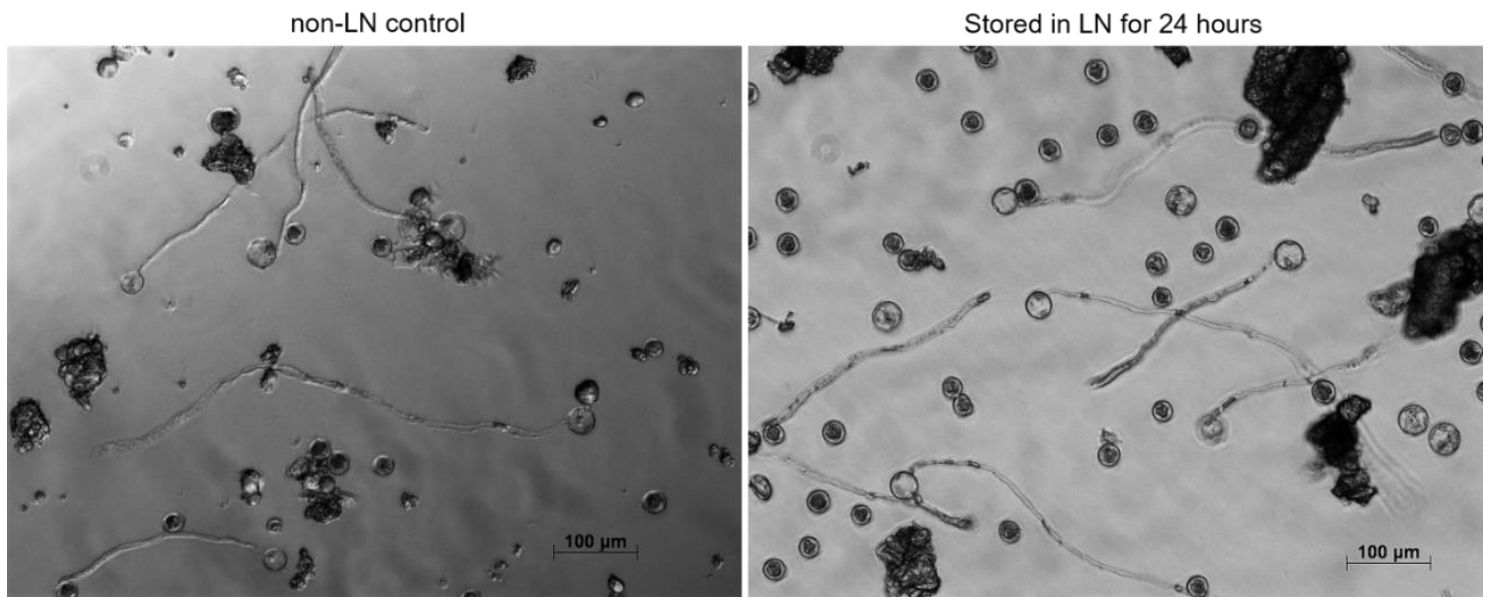

Figure 5. Representative photographs from pollen germination assay (PGA) of pollen stored for $24 \mathrm{~h}$ in liquid nitrogen (LN). Desiccated cannabis pollen mixed with 1:10 wheat flour and stored in liquid nitrogen (LN). Non-LN control (control was subjected to the same desiccation combined with whole baked wheat flour). Pollen flour mix was diluted to $0.1 \mathrm{mg} / \mathrm{mL}$ in PGM and used for PGA.

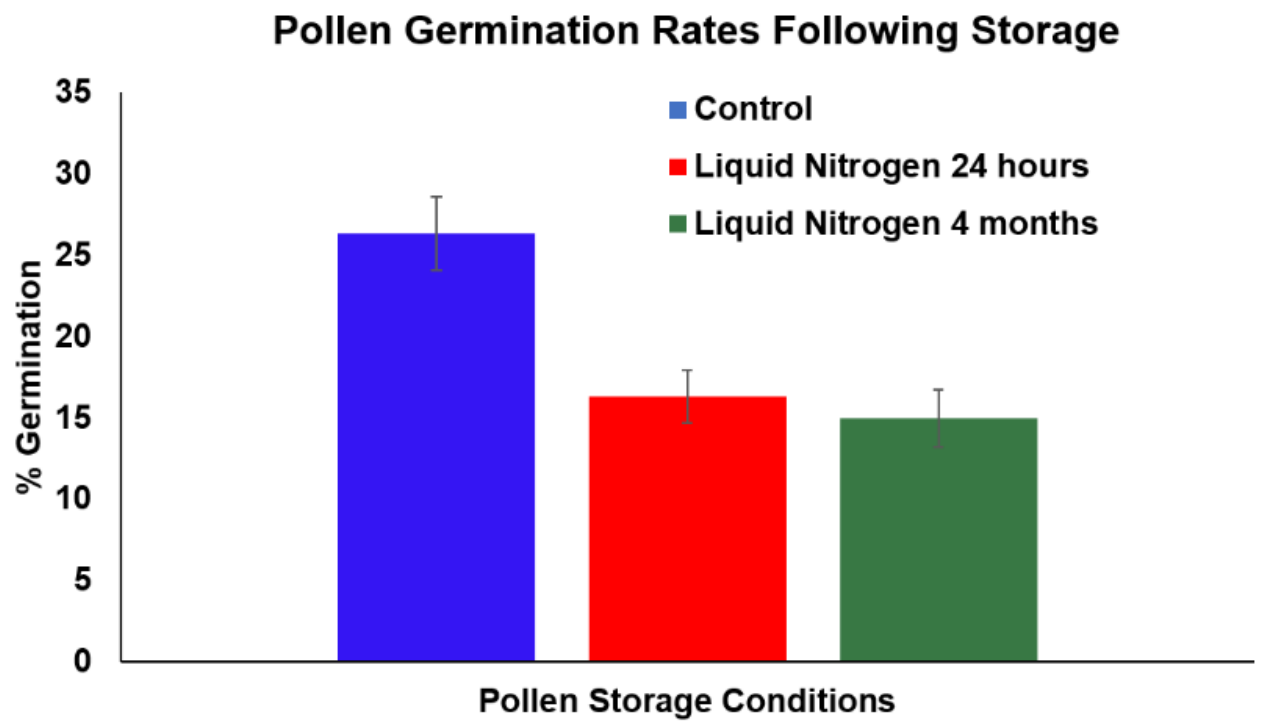

Figure 6. Comparison of pollen germination efficiency between desiccated pollen combined with whole baked wheat flour and stored in liquid nitrogen (LN) for $24 \mathrm{~h}$ or 4 months and non- liquid nitrogen control (control was subjected to same desiccation protocol combined with whole baked wheat flour). Data were shown as mean \pm SE. The germination efficiency data were statistically analyzed by generalized linear models (GLM) with binomial distribution (link logit) using the GLM function in software R Studio 1.2.1335.

There are several reports on pollen long-term cryopreservation including one-year viability (Allium sp., [12]; Juglans nigra, [13]; Diospyros khaki [14]), two years viability (Jojoba, [15]; hop, [16]), and five or more years survival (Vitis vinifera L., [17]; tomato and eggplant, [18]; Maize, [19]; Gladiolus [20]). Our cryopreservation method resulted in a slight decrease in germination (but not significant, GLM test $p>0.05$ ) after $24 \mathrm{~h}$ and four-month of LN storage (Figure 6). Hamzah and Chan (1986) suggested viability declines over a relatively short time [21]. Hevea pollen exhibited a decline from $20 \%$ in vitro germination after one month to $2 \%$ after five months of storage in LN. Some pine and spruce pollen stored in LN also showed a decline in viability over a 24-month period [22]. Cryopreservation of maize, lily [23] and wheat pollen [24] also exhibited a decline in viability during cryopreservation. Overall, 
these results suggest that periodic viability testing of cryopreserved pollen is required to ensure the future viability of stored pollen in breeding.

In conclusion, we have standardized a simple assay for quickly assessing pollen germination in Cannabis sativa. Through the use of DAPI staining on germinating pollen cells, we were able to track the migration of sperm nuclei descending the pollen tube. This indicates that Cannabis sativa releases pollen in a bicellular state, where the second mitosis event occurs after pollen tube germination. By using our PGA, we have demonstrated the loss of pollen viability over time when stored at $4{ }^{\circ} \mathrm{C}$ and suggested an optimal time during flower development for pollen collection to maximize longevity during storage. Finally, we have provided an easy protocol for cryopreservation using desiccation combined with baked wheat flour and subsequent long-term storage of cannabis pollen in liquid nitrogen.

\section{Materials and Methods}

\subsection{Plant Material and Growth Conditions}

Cannabis sativa plants (strain name "Spice", THC dominant) were grown under full spectrum 300-Watt LED grow lights (PrimeGarden) with $16 \mathrm{~h}$ light for vegetative growth and $12 \mathrm{~h}$ light for flowering at $22{ }^{\circ} \mathrm{C}$.

\subsection{Pollen Germination Assay (PGA)}

\subsubsection{Pollen Germination Media (PGM)}

The composition of pollen germination medium was adapted from Schreiber and Dresselhau (2003) [25] with some modification. The original pollen germination medium from Schreiber and Dresselhau (2003) [25] employed 1\% noble agar. In our study, we tested pollen germination media as liquid or combined with $1 \%$ agar. We found that liquid media resulted in better image acquisition and quantification of germination than solid media. Therefore, we employed liquid medium for all pollen germination experiments. During optimization of the Pollen Germination Assay (PGA), pollen concentrations of $0.1,1$ and $10 \mathrm{mg} / \mathrm{mL}$ were employed with the pollen diluted in PGM and incubated for $16 \mathrm{hr}$.

A $2 \times$ PGM contained the following: $10 \%$ sucrose (BIOSHOP), $0.005 \% \mathrm{H}_{3} \mathrm{BO}_{3}$ (Sigma), $10 \mathrm{mM}$ $\mathrm{CaCl}_{2}$ (BIOSHOP), $0.05 \mathrm{mM} \mathrm{KH}_{2} \mathrm{PO}_{4}$ (Merk) and 6\% PEG 4000 (Fluka). After components were added to distilled $\mathrm{H}_{2} \mathrm{O}$, heated on a stir plate for $10 \mathrm{~min}$ at $70{ }^{\circ} \mathrm{C}$ then filter sterilized. A $1 \times$ working solution was prepared fresh each day by diluting in distilled $\mathrm{H}_{2} \mathrm{O}$.

\subsubsection{Pollen Collection and Optimization of the PGA}

Pollen was obtained from flowering male Cannabis sativa plants using a vacuum manifold method [26]. For the standardized PGA, $10 \mathrm{mg}$ of cannabis pollen was combined with $1 \mathrm{~mL}$ of freshly prepared $1 \times$ PGM and diluted to $0.1 \mathrm{mg} / \mathrm{mL}$. $200 \mu \mathrm{L}$ was then pipetted into a 24-well tissue culture plate (Flat Bottom Cell+, Sarstedt) and sealed with parafilm. Plates were incubated in the dark at $22{ }^{\circ} \mathrm{C}$ for $16 \mathrm{~h}$ and examined using an inverted light microscope (Zeiss Axio Observer Z1, Oberkochen, Germany). To obtain a representation of germination profile, a time-lapse of a pollen germination assay (PGA) was performed. We have observed the germination profile for $6 \mathrm{~h}$ with 30 min interval. The final germination was calculated after $16 \mathrm{~h}$ incubation.

\subsection{Imaging and Germination Assessment}

Images were taken using phase contrast at $100 \times$ magnification. For each treatment, the germination experiment was repeated at least three times with three biological replicates. For each technical replicate, 8 images were taken to get an accurate representation of germination. Pollen germination percentages were calculated by dividing the number of germinating pollen grains by the total number of pollen grains. Germination percentages for each replicate represent the averages of the eight images. 


\subsection{DAPI Staining of Cannabis Pollen to Decipher Its Bicellular or Tricellular Nature}

Collected pollen was stained with DAPI (4',6-diamidino-2-phenylindole) and imaged using an inverted fluorescent microscope (Zeiss Axio Observer Z1). The DAPI staining protocol was adapted from Backues et al. 2010 [27]. Germinated pollen was suspended in pollen isolation buffer (PIB) containing $100 \mathrm{mM} \mathrm{NaPO}_{4}$ (pH 7.5), 1 mM EDTA, 0.1\% (v/v) Triton X-100 and $1 \mu \mathrm{g} / \mathrm{mL}$ DAPI. A drop of solution was placed on a coverslip, incubated at room temperature for $5 \mathrm{~min}$ and viewed with the DAPI filter set. For DAPI staining of germinated pollen, pollen germination was performed as previously described, and staining was conducted with $1 \mu \mathrm{g} / \mathrm{mL}$ DAPI after $16 \mathrm{~h}$ in PGM.

\subsection{Pollen Collection from Different Development Stages to Assess the Loss of Pollen Viability over Time}

Pollen was collected from male Cannabis sativa plants at different stages of the flower development. The four stages of flowering were chosen according to the $\mathrm{BBCH}$ (Biologische Bundesantalt, Bundessortenamt and Chemische) scale adapted for cannabis [28] and are listed as follows with the BBCH notation in brackets: Early (62), Mid (64), Mid-Late (65) and Late (67).

Following collection, an aliquot from each developmental stage was taken and used in the PGA for germination rate at time of collection (T0). The rest of the aliquots were stored in a $1.5 \mathrm{~mL}$ centrifuge tube at $4{ }^{\circ} \mathrm{C}$ in the dark. After one week, an aliquot from the different developmental stages was used for the PGA (T1), again after 2 weeks (T2) and again after 3 weeks (T3).

\subsection{Cryopreservation of Pollen}

Cannabis pollen submerged in Liquid Nitrogen (LN) without the use of any cryoprotectant or treatment will fail to germinate after the formation of ice crystals [29,30]. Cannabis pollen was combined with cryoprotectants DMSO or glycerol diluted to concentrations of $10 \%, 20 \%, 30 \%$ and $60 \%$ and submerged in LN. Following $24 \mathrm{~h}$ in LN, pollen was removed and used in the PGA as previously described.

\subsection{Desiccation of Pollen Prior to Cryopreservation}

Cannabis pollen was combined with all purpose baked wheat flour $(1: 10 w / w)$ in a $1.5 \mathrm{~mL}$ centrifuge tube and desiccated at 5, 15 and $25 \mathrm{kPa}$ for 20 or $40 \mathrm{~min}$. Following desiccation, the tube was placed in $\mathrm{LN}$ for four months, removed and placed at $22{ }^{\circ} \mathrm{C}$ for $10 \mathrm{~min}$. The pollen/wheat flour mix was then used for the PGA, as previously described.

\subsection{Statistical Analyses}

Mean pollen germination over time at four different development stages and mean pollen germination efficiency between pollen stored in liquid nitrogen (LN) for $24 \mathrm{~h}, 4$ months and non- liquid nitrogen control were calculated in an excel sheet. Data were shown as mean $\pm \mathrm{SE}$. The germination efficiency data were analyzed by generalized linear models (GLM) with binomial distribution (link logit) using the GLM function in software R Studio 1.2.1335.

Supplementary Materials: The following are available online at http://www.mdpi.com/2223-7747/9/5/665/s1, Figure S1: The representative photographs of the male inflorescences at various stages of flower development; Figure S2: Representative photographs from pollen germination assay (PGA); Figure S3: Photographs of harvested seeds from (A) flower pollinated with control fresh pollen, and (B) flower pollinated with stored pollen; Video S1: Time-lapse video of cannabis pollen germination.

Author Contributions: Conceptualization, D.G., A.B., N.S.Y., and I.K.; methodology, D.G., A.B. and N.S.Y.; validation, D.G., A.B., N.S.Y. and A.S.; investigation, D.G., N.S.Y., A.B. and A.S.; resources, I.K.; data curation, D.G., N.S.Y., A.S., A.B. and I.K.; writing—original draft preparation, D.G. and N.S.Y.; writing-review and editing, D.G., N.S.Y., A.S., A.B. and I.K.; visualization, D.G., N.S.Y. and I.K.; supervision, I.K.; project administration, I.K.; funding acquisition, I.K. All authors have read and agreed to the published version of the manuscript.

Funding: This research was funded by MITACS and Natural Sciences and Engineering Research Council of Canada (NSERC). 
Acknowledgments: We thank the Natural Sciences and Engineering Research Council of Canada (NSERC) and MITACS for funding our work. Jitendra Keshri from Western University of Health Sciences, California, has been acknowledged for help in data analysis in R Studio.

Conflicts of Interest: The authors declare that they have no competing interests.

\section{References}

1. Piluzza, G.; Delogu, G.; Cabras, A.; Marceddu, S.; Bullitta, S. Differentiation between fiber and drug types of hemp (Cannabis sativa L.) from a collection of wild and domesticated accessions. Genet. Resour. Crop. Evol. 2013, 60, 2331-2342. [CrossRef]

2. Chandra, S.; Lata, H.L. Botany and Biotechnology; Springer International Publishing: Cham, Switzerland, 2017; ISBN 9783319545639.

3. Choudhry, N.; Siddiqui, M.; Bi, S.; Khatoon, S. Effect of seasonality and time after anthesis on the viability and longevity ofCannabis sativapollen. Palynology 2014, 38, 235-241. [CrossRef]

4. Zottini, M.; Mandolino, G.; Ranalli, P. Effects of $\gamma$-ray treatment onCannabis saliva pollen viability. Plant Cell Tissue Organ Cult. 1997, 47, 189-194. [CrossRef]

5. Engelmann, F.; Takagi, H. Cryopreservation of Tropical Plant Germplasm: Current Research Progress and Applications; JIRCAS: Tsukuba, Japan, 2000; ISBN 9290434287.

6. Williams, J.; Taylor, M.L.; O’Meara, B. Repeated evolution of tricellular (and bicellular) pollen. Am. J. Bot. 2014, 101, 559-571. [CrossRef] [PubMed]

7. Towill, L.E. Low Temperature and Freeze-/Vacuum-Drying Preservation of Pollen; CRC Press: Boca Raton, FL, USA, 1985.

8. Buitink, J.; Claessens, M.M.; Hemminga, M.A.; Hoekstra, F.A. Influence of Water Content and Temperature on Molecular Mobility and Intracellular Glasses in Seeds and Pollen. Plant Physiol. 1998, 118, 531-541. [CrossRef]

9. Kartha, K.K. Meristem culture and germplasm preservation. In Cryopreservation of Plant Cells Organs; CRC Press: Boca Raton, FL, USA, 1985; pp. 115-134.

10. Woodell, S.R.J.; Pritchard, H.W. Modern Methods in Orchid Conservation: The Role of Physiology, Ecology and Management. J. Ecol. 1990, 78, 851. [CrossRef]

11. Yi, W.; Law, E.S.; Wetzstein, H.Y. Polyester and nylon powders used as pollen diluents preserve pollen germination and tube growth in controlled pollinations. Sex. Plant Reprod. 2003, 15, 265-269. [CrossRef]

12. Kanazawa, T.; Kobayashi, S.; Yakuwa, T. Flowering Process, Germination and Storage of Pollen in Allium victorialis L. ssp. platyphyllum Hult. J. Jpn. Soc. Hortic. Sci. 1992, 60, 947-953. [CrossRef]

13. Luza, J.G.; Polito, V.S. Cryopreservation of English walnut (Juglans regia L.) pollen. Euphytica 1988, 37, 141-148. [CrossRef]

14. Wakisaka, I. Ultra low temperature storage of pollens of Japanese persimmons (Diospyros Kaki LINN. f). J. Jpn. Soc. Hortic. Sci. 1964, 33, 291-294. [CrossRef]

15. Lee, C.W.; Thomas, J.C.; Buchmann, S.L. Factors affecting vitro germination and storage of jojoba pollen. J. Am. Soc. Hortic. Sci. 1985, 110, 671-676.

16. Haunold, A.; Stanwood, P. Long-Term Preservation of Hop Pollen in Liquid Nitrogen 1. Crop. Sci. 1985, 25, 194-196. [CrossRef]

17. Ganeshan, S.; Alexander, M.P. Fertilizing ability of cryopreserved grape (Vitis vinifera L.) pollen. Vitis 1990, $29,145-150$.

18. Alexander, M.P.; Ganeshan, S. Preserving viability and fertility of tomato and egg plant pollen in liquid nitrogen. Indian J. Plant Genet. Resour. 1989, 2, 140-144.

19. Barnabás, B. Preservation of Maize Pollen. In Genetic Modification of Plants; Springer Science and Business Media LLC: Berlin, Germany, 1994; Volume 25, pp. 607-618.

20. Rajasekharan, P.E.; Rao, T.M.; Janakiram, T.; Ganeshan, S. Freeze preservation of gladiolus pollen. Euphytica 1994, 80, 105-109. [CrossRef]

21. Hamzah, S.; Chan, J.L. Pollen Storage of Hevea. J Natural Rubber Res 1996, 11, 115-124.

22. Lanteri, S.; Belletti, P.; Lotito, S. Storage of pollen of Norway spruce and different pine species. Silvae Genet. 1993, 42, 104. 
23. Nath, J.; Anderson, J.O. Effect of freezing and freeze-drying on the viability and storage of Lilium longiflorum L. and Zea mays L. pollen. Cryobiology 1975, 12, 81-88. [CrossRef]

24. Andreica, A.; Sparchez, C.; Soran, V. Germination of wheat pollen under normal and cryopreservation conditions. Stud. Cercet. Biol. Ser. Biol. Veg. 1988, 40, 55-58.

25. Schreiber, D.N.; Dresselhaus, T. In vitro pollen germination and transient transformation ofZea mays and other plant species. Plant Mol. Boil. Rep. 2003, 21, 31-41. [CrossRef]

26. Johnson-Brousseau, S.A.; McCormick, S. A compendium of methods useful for characterizing Arabidopsis pollen mutants and gametophytically-expressed genes. Plant J. 2004, 39, 761-775. [CrossRef] [PubMed]

27. Backues, S.K.; Korasick, D.A.; Heese, A.; Bednarek, S.Y. The Arabidopsis Dynamin-Related Protein2 Family Is Essential for Gametophyte Development[C][W]. Plant Cell 2010, 22, 3218-3231. [CrossRef] [PubMed]

28. Mishchenko, S.; Mokher, J.; Laiko, I.; Burbulis, N.; Kyrychenko, H.; Dudukova, S. Phenological growth stages of hemp (Cannabis sativa L.): Codification and description according to the BBCH scale. Žemés ūkio Moksl. 2017, 24, 24. [CrossRef]

29. Towill, L.E.; Walters, C. Cryopreservation of pollen. Cryopreserv. Trop. Plant Germplasm 2000, 115-129.

30. Bajaj, Y. Cryopreservation of Pollen and Pollen Embryos, and the Establishment of Pollen Banks. Adv. Appl. Microbiol. 1987, 107, 397-420. [CrossRef]

(C) 2020 by the authors. Licensee MDPI, Basel, Switzerland. This article is an open access article distributed under the terms and conditions of the Creative Commons Attribution (CC BY) license (http://creativecommons.org/licenses/by/4.0/). 